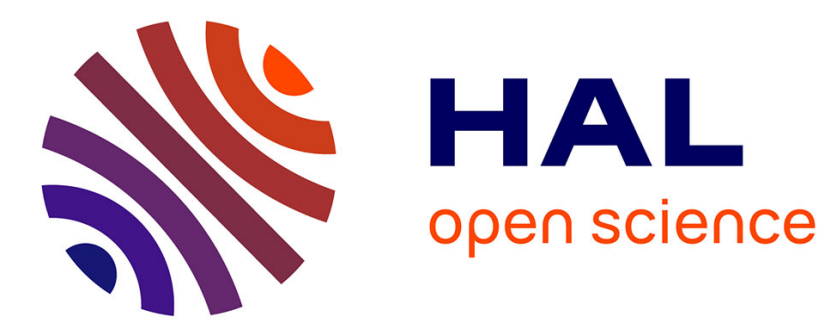

\title{
PHYSICAL PROPERTIES OF EuO VERSUS ELECTRONIC CONCENTRATIONS
}

\author{
C. Godart, A. Mauger, J. Desfours, J. Achard
}

\section{To cite this version:}

C. Godart, A. Mauger, J. Desfours, J. Achard. PHYSICAL PROPERTIES OF EuO VERSUS ELECTRONIC CONCENTRATIONS. Journal de Physique Colloques, 1980, 41 (C5), pp.C5-205-C5-214. 10.1051/jphyscol:1980535 . jpa-00219970

\section{HAL Id: jpa-00219970 https://hal.science/jpa-00219970}

Submitted on 1 Jan 1980

HAL is a multi-disciplinary open access archive for the deposit and dissemination of scientific research documents, whether they are published or not. The documents may come from teaching and research institutions in France or abroad, or from public or private research centers.
L'archive ouverte pluridisciplinaire HAL, est destinée au dépôt et à la diffusion de documents scientifiques de niveau recherche, publiés ou non, émanant des établissements d'enseignement et de recherche français ou étrangers, des laboratoires publics ou privés. 


\author{
C.GODART, A. MAUGER, ${ }^{++}$J.P. DESFOURS ${ }^{+++}$and J.C. ACHARD! \\ +Chimie Métaliurgique et spectroscopie des Terres Rares, E.R. 209, C.N.R.S. 92190 - MEUDON, ERANCE. \\ Loboratoire de Physique des Solides, C.N.R.S. 92190 - MEUDON, FRANCE. \\ C.E.E.S., Université des Sciences, 34060 - Montpellier, France.
}

\begin{abstract}
Résumé.- Des monocristaux homogènes d'Eu0, Euo riche en Eu, et Eúo dopé au gadolinium ont été obtenus et caractérisés par dés analyses : aux rayons $\mathrm{x}$, avec des microsondes et par des mesures, en fonction de la température, d'effet Mossbauer, de spectroscopie infra-rouge et de résistivité. Des résultats de photoconductivité, effet Hall, mesures optiques et magnétiques sont apportés. Ils sont interprétés dans le cadre d'un modèle simple tenant compte des énergies de coulomb, cinétique et d'échange et du degré de compensation d'un niveau donneur, ce niveau étant dû̀ à $\mathrm{l}$ 'existence de lacunes d'oxygène ou d'atomes de Gd.

Abstract.- Homogeneous single crystals of Eu0, Eu rich EuO and Gd doped EuO have been obtained and characterized by X-ray, microprobe analysis; Mossbauer, infrared spectroscopy and resistivity measurements versus temperature. Photoconductivity, Hall effect, optical and magnetic measurements are reported. They are interpreted within a simple model taking into account Coulomb, kinetic and exchange energies and considering the degree of compensation of the donor level due to oxygen vacancies or Gd atoms.
\end{abstract}

Introduction.- Europium oxide Eu0 is a magnetic semiconductor which was the subject of many studies due to the following reasons. Its simple crystalline structure (NaCl) simplifies the study of magnetic interactions in this ferromagnetic compound. In addition, by departure from stoechiometry or by doping, a drastic change of the carrier concentration can be achieved resulting in noticeable variations of physical properties; then it is needed to perform the measurements of physical properties on single crystals. For example, with a moderate concentration of oxygen vacancies a Metal Insulator Transition (MIT) appears at about $50 \mathrm{k}^{/ 1}$. Numerous theoretical studies of this transition involving the concept of Bound Magnetic Polaron (BMP) $/ 2 /$ showed that the magnetic interactions have a strong effect
on transport properties. Reciprocally, the electronic properties of the material affect the nature of the exchange interaction induced by free carriers. Optical spectra of Eu rich Eu0 evidence structures which also were correlated to the magnetic interactions. Because of this interdependence between various physical properties it seemed to us that it was interesting to investigate them as a whole with a restricted number of samples. The growing technics of crystals build the first section. The results of characterization measurements not only direct (X-rays, microprobe analysis) but also indirect (infrared absorption spectra, Mössbauer effect, resistivity measurements) are the subject of section 2 . We report transport measurements including photoconductivity data in section 3 , reflectivity measurements in section 4, and magnetization measurements in section 5 . In the last section we present a simple model taking into account a) the contributions of exchange, coulomb and kinetic energies to the binding energy of the donor state ; b) the statistics of free carriers. This model accounts for the experimental properties as a whole.

I Growing technics.- Euo single crystals were first obtained by Guerci and Shafer $13 /$ from the reaction of $\mathrm{Eu}$ metal on $\mathrm{Eu}_{2} \mathrm{O}_{3}$ in a sealed metallic refractory crucibles; followed by a slow cooling of the melt. We have used a similar method: the crucible (Mo) is filled $\left(\mathrm{Eu}_{2}{ }_{3}\right.$ : 99.99\%; Eu: 99.9\%) in a glove box under purified axgon atmosphere and sealed by arc welding. The sample is twice melted at about $2000^{\circ} \mathrm{C}$ with intermediate 
inversion of the crucible and then slowly cooled at a rate of $3.6^{\circ} \mathrm{C} / \mathrm{h}$ to $1600^{\circ} \mathrm{C}$, faster by extreme values of these measurements. below this temperature. Using this procedure good crystals are obtained and the values of their atomic ratios $E u / 0$ are fairly well correlated with the initial values of this ratio in the charge; thus to obtain crystals with different ratios in the range; 0.98 to 1.01 , initial ratios in the charge must be taken from 0.98 to 1.04. But we have noted that if the cooling rate is increased, this relationship changes and the final ratio $E u / 0$ becomes larger, as it can be seen in table I (samples $A$ and 3 ) and in reference /4/. These results are in agreement with those of Fischer and al./5/. With the double crucible technique, Shafer and al./6/ used a larger ratio range in the initial charge (from 1 to slightly above 2). Solidification temperature values that we have determined agree with the phase diagram established by shafer and al./6/.

The (Eu,Gd) 0 samples ( numbered from 11 to 19 ) are grown with the procedure used for $\mathrm{Eu}_{\mathrm{x}} 0$ crystals. The initial ratio $(\mathrm{Eu}+\mathrm{Gd}) / 0$ is taken equal to 1.02 (except in runs 16 and 17) since in the case of Euo this value led to stoichiometric crystals. We report in table $I$ the $E u / O$ and $G d / 0$ initial ratios and the Gd weight concentrations in crystals assuming a final ratio $\mathrm{Eu}+\mathrm{Gd} / 0$ of 1 .

2. Characterisation.- Micrographic examination shows that the samples are monophase, except samples $1,18,19$ in which very small amounts of inclusions are present and may be identified to $\mathrm{Eu}_{3} \mathrm{O}_{4}(1,18,19)$ and $\mathrm{Gd}_{2} \mathrm{O}_{3}(18$, 19) by microprobe analysis.

A full spectra of crystals impurities are performed with a Ion Analyser (IMS 300 Cameca), the concentration of all of these are too low ( $<500 \mathrm{ppm}$ ) to be determined accurately using a MS 46 electronic microprobe analyser.

The repartition of gadolinium in the samples is checked by electron microprobe analysis, figure 1 represents the $\mathrm{x}$ ray picture of Gd $(L \alpha)$ of a $(200 \mu \mathrm{m})^{2}$ area of sample 16 ( $2 \%$ Gd) showing a good homogeneity. The Gadolinium concentration is given by the mean value of the analyses performed in different points across the whole crystal, and the concentration gradient is given

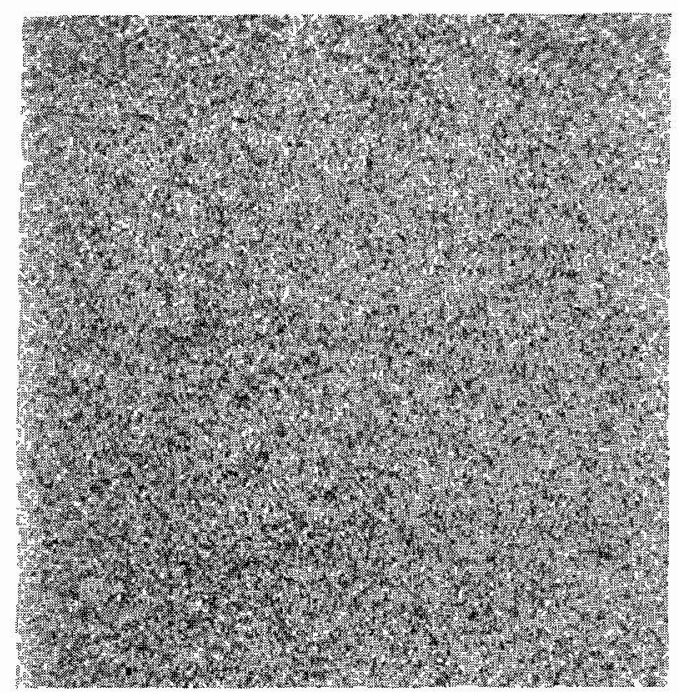

Fig 1. Gd distribution in EuO $n^{\circ} 16$. Detected with $\mathrm{L} \alpha$ ray of $\mathrm{Gd}$.

In table I are reported the gadolinium concentration and the gradient expressed as a deviation of the concentration value. Gradient values are small except for sample 15.

The departure from stoichiometry in $\mathrm{Eu}_{\mathrm{x}} 0$ samples cannot be determined by direct analysis. In fact, using the method and the results of shafer and al. $/ 6 /$ assuming the hypothesis that an europium excess appears like oxygen vacancies and europium defect like $\mathrm{Eu}^{3+}$ appearance, we have estimated the vacancy concentration by indirect physical measurements.

Mössbauser measurements performed between 4.2 and $300 \mathrm{~K}^{/ 7 /}$ reveal the existence of $\mathrm{Eu}^{3+}$ ions only in the samples $1,2,3$, among $\mathrm{Eu}_{\mathrm{x}} \mathrm{O}$ samples. These samples set on the 0 rich side.

The absorption coefficient $\alpha$ at the wavelength $\lambda=2 \mu \mathrm{m}$ measured at room temperature on $7200 \mu \mathrm{m}$ thick polished samples increases from $25 \mathrm{~cm}^{-1}$ in EuO $\mathrm{n}^{\circ} 3$ to more than $100 \mathrm{~cm}^{-1}$ in EuO $\mathrm{n}^{\circ} 8$. In the samples like 5 and 8 (Fig. 3) the presence of oxygen vacancies can be deduced from the existence of an absorption peak at $2.2 \mu \mathrm{m}$. Moreover in samples like 8 , the high value of $\alpha$ indicated the presence of free carriers. In the sample 3 (Fig. 3), the low value of $\alpha$ indicated that it is near stoichiometry The measurements of the resistivity variations versus temperature down to $4.2 \mathrm{~K}$ 
reported on the figure 4 permit to estimate more accurately the vacancy concentration.

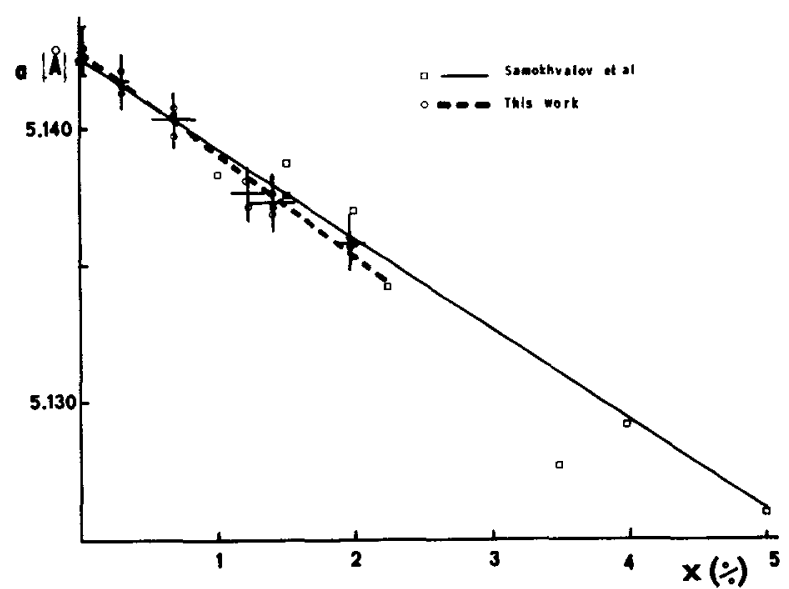

Fig 2. Lattice parameter of $\mathrm{Eu}_{1-x} \mathrm{Gd} \mathrm{X}^{\mathrm{O}}$ as a function of $\mathrm{x}$.

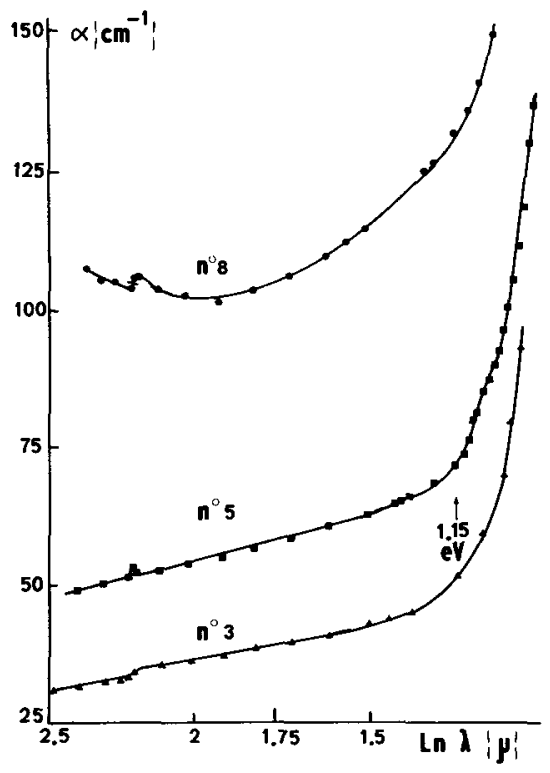

Fig 3. Absorption coefficient on $\# 200 \mu \mathrm{m}$ thick samples.

The activation energy $E_{a}$ ranging from 0.6 to $0.3 \mathrm{eV}$ indicates a crossing throught the stoichiometry from o rich (sample 3) to Eu rich (samples $4,5,6$ ) with the increase of the vacancy concentration. Metal Insulator Transition appears at about $50 \mathrm{~K}$ with about $0.3 \%$ vacancy concentration. "Metallic" behaviour is observed in samples ( 7 to 10 ) for an increase of the concentration from 0.3 to 0.5 응.
The lattice parameter of the compounds is determined on powdered samples by DebyeScherrer method. For $\mathrm{Eux}_{1} 0$, the measured values in the whole studied concentration remain constant and equal to $5.143 \pm 0.001 \AA$, this value is in agreement with previous measurements $/ 6,8 \%$. For ( $E \mathrm{u}, \mathrm{Gd}) 0$ compounds the lattice parameter decreases from $5.143 \AA$ to $5.136 \AA$ when the Gd concentration changes from 0 to about 2\%. At these low concentrations, the variation is linear, as it can be seen on figure 2, in a fairly good agreement with Samokhvalov results up to $5 \%$ (9).

3. Transport properties.- For (Eu,Ga) 0 samples the resistivity curves versus temperature are reported in figures, 4 and 5 . When the concentration of $\mathrm{Gd}$ is small ( $<1 \%$ ) a semiconducting behaviour is observed between $300 \mathrm{~K}$ and about $200 \mathrm{~K}$ with an activation energy of $0.3 \mathrm{ev}$.

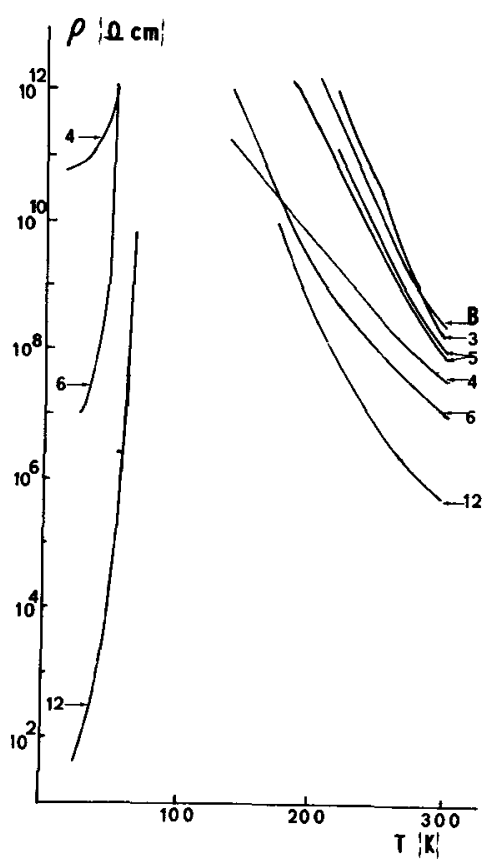

Fig. 4. Resistivity versus temperature on semiconducting Euo samples.

The resistivities at room temperature decrease from $\neq 6 \times 10^{7}$ to $5 \times 10^{5} \Omega \mathrm{cm}$ when the Gd concentration increases from 0.28 to $0.64 \%$. In this last sample, the resistivity decreases from $10^{10} \Omega \mathrm{cm}$ at $65 \mathrm{~K}$ to a value smaller than $5 \times 10^{1} \Omega$. $\mathrm{cm}$ at $30 \mathrm{~K}$ (Fig. 4). When the Gd concentration is higher 
than $1 \%$ the resistivity curves have a metallic character in the whole range of temperatures (Fig 5.) tive to the nature of dopants. In particular the resistivity curve of ( $\mathrm{Eu} G d$ ) $0 \mathrm{n}^{\circ} 12$ is very similar to the resistivity curve of

\begin{tabular}{|c|c|c|c|c|c|c|c|c|c|c|}
\hline $\mathrm{N}^{0 \mathrm{~S}}$ & \begin{tabular}{|l|} 
Initial \\
compos. \\
for 1 \\
oxygen \\
\end{tabular} & From & $\begin{array}{l}\text { Cooling } \\
\text { speed }\end{array}$ & $\mid \begin{array}{c}\text { Final } \\
\text { compos. }\end{array}$ & $\begin{array}{l}P_{4.2 \mathrm{~K}} \\
\Omega \cdot \mathrm{cm}\end{array}$ & $\begin{array}{l}P_{300 \mathrm{~K}} \\
\Omega_{\bullet \mathrm{cm}}\end{array}$ & $\begin{array}{r}E_{A} \\
m e V\end{array}$ & $\begin{array}{l}{ }^{\mathrm{T}} \mathrm{C} \\
\mathrm{k}\end{array}$ & $\begin{array}{c}\mathrm{n}_{4.2 \mathrm{~K}} \mathrm{~K} \\
\mathrm{~cm}^{-3}\end{array}$ & $\begin{array}{l}n 300 k \\
\mathrm{~cm}^{-3}\end{array}$ \\
\hline A & $\begin{array}{ll}E u & \\
& 1,022\end{array}$ & 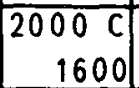 & $20 \mathrm{C} / \mathrm{h}$ & $\begin{array}{c}0.5 \% \\
0 \mathrm{Vac}\end{array}$ & 0.17 & 0.5 & 0 & & & $1.1 \times 10^{19}$ \\
\hline B & ${ }^{E u}{ }_{1.030}$ & 11 & \begin{tabular}{|l|} 
Quench \\
from 1600
\end{tabular} & $\begin{array}{c}\mathrm{Eu}_{3} \mathrm{O}_{4} \\
\text { dinclusion }\end{array}$ & $-10^{12}$ & $2.1 \times 10^{8}$ & 490 & & & \\
\hline 1 & $E u_{0.98}$ & " & $3.6^{\circ} \mathrm{C} / \mathrm{h}$ & $E u^{3+}$ & & & & & & \\
\hline 2 & $E_{1,010}$ & $"$ & $"$ & $"$ & & & & & & \\
\hline 3 & $\mathrm{Eu}{ }^{1.022}$ & " & " & \begin{tabular}{cc|} 
& $0 \%$ \\
0 & $\mathrm{Vac}$ \\
\end{tabular} & $-10^{12}$ & $1.8 \times 10^{8}$ & 600 & 69.3 & & \\
\hline 4 & $E u, 024$ & $"$ & $5^{\circ} \mathrm{C} / \mathrm{h}$ & $\begin{array}{ccc}-0 & 0 & \% \\
0 & \mathrm{Vac}^{*}\end{array}$ & $6 \times 10^{10}$ & $3.5 \times 10^{7}$ & 290 & & & \\
\hline 5 & \begin{tabular}{|ll}
$E u$ & \\
& 1.024 \\
\end{tabular} & " & $3.6^{\circ} \mathrm{C} / \mathrm{h}$ & $\begin{array}{lll}-0 & 0 & 1 \\
0 & \mathrm{Vac}^{*}\end{array}$ & $>10^{12}$ & $9 \times 10^{7}$ & 450 & 69.3 & & \\
\hline 6 & \begin{tabular}{|l|l|}
$E u$ & \\
& 1.025 \\
\end{tabular} & $"$ & $"$ & $\begin{array}{r}0.3 \% \\
0 \quad \mathrm{Vac} \\
\end{array}$ & $<10^{7}$ & $10^{7}$ & 270 & & & \\
\hline 7 & $E u$ u & $"$ & " & $\begin{array}{c}0.5 \% \\
.0 \mathrm{Vac} \\
\end{array}$ & 0.16 & 1.5 & 0 & & & \\
\hline 8 & $\begin{array}{|ll|}E u & \\
& 1.033 \\
\end{array}$ & " & " & $\begin{array}{c}0.4 \% \\
0 \quad \mathrm{Vac} * \\
\end{array}$ & $1.1 \times 10^{-3}$ & 1.7 & 0 & 69.3 & $1.1 \times 10^{19}$ & $2.4 \times 10^{18}$ \\
\hline 9 & $\mathrm{Eu}_{1,03 \pi}$ & " & " & $\begin{array}{l}0.5 \% \\
0 \quad \mathrm{Vac} * \\
\end{array}$ & $2.5 \times 10^{-2}$ & $8 \times 10^{-2}$ & 0 & & & \\
\hline 10 & $\begin{array}{lll}E u & & \\
& 1,037\end{array}$ & $"$ & $"$ & $"$ & 0.25 & 0.6 & 0 & & & \\
\hline 11 & $\begin{array}{lll}\text { Eu } & 1.015 \\
\text { Gd } & 0.005 \\
\end{array}$ & " & $"$ & $\begin{array}{l}0.28 \% G d \\
\pm 0.04 \\
\end{array}$ & $-5 \times 10^{10}$ & $5.8 \times 10^{7}$ & 300 & 69.3 & & \\
\hline 12 & \begin{tabular}{ll|} 
Eu & 1.01 \\
Gd & 0.01 \\
\end{tabular} & $"$ & $"$ & $\begin{array}{c}0.64 \% \text { Gd } \\
\pm 0.15\end{array}$ & $<5 \times 10^{1}$ & $5.1 \times 10^{5}$ & 320 & 70 & & \\
\hline 13 & $\begin{array}{lll}\text { Eu } & 1.005 \\
\text { Gd } & 0.015 \\
\end{array}$ & " & " & $\begin{array}{r}1.11 \% \mathrm{Gd} \\
\pm 0.12 \\
\end{array}$ & $8 \times 10^{-4}$ & $4 \times 10^{-3}$ & 0 & $\begin{array}{c}72 \\
100 \\
\end{array}$ & $8 \times 10^{19}$ & $1.5 \times 10^{20}$ \\
\hline 14 & $\begin{array}{l}E u \\
\text { Gd } 1.0025 \\
0.0175\end{array}$ & " & " & $\begin{array}{l}1.25 \% \mathrm{Gd} \\
\pm 0.17 \\
\end{array}$ & $1.1 \times 10^{-4}$ & $1.3 \times 10^{-3}$ & 0 & 116 & $1 \times 10^{20}$ & $2 \times 10^{20}$ \\
\hline 15 & $\begin{array}{ll}E u & 1.00 \\
\text { Gd } & 0.02 \\
\end{array}$ & " & " & $\begin{array}{c}1.74 \% .6 d \\
\pm 0.44 \\
\end{array}$ & $5 \times 10^{-5}$ & $1 \times 10^{-3}$ & 0 & 148 & $5 \times 10^{20}$ & $8 \times 10^{20}$ \\
\hline 16 & $\begin{array}{ll}E u & 1.02 \\
\text { Gd } & 0.02 \\
\end{array}$ & " & $"$ & $\begin{array}{c}1.73 \% \mathrm{Gd} \\
\pm 0.10 \\
\end{array}$ & & & & 148 & & \\
\hline 17 & $\left|\begin{array}{cc}E u & 1.02 \\
\text { Gd } & 0.035\end{array}\right|$ & $"$ & " & & & & & & & \\
\hline 18 & $\begin{array}{rr}\text { Eu } & 0.98 \\
0.04 \\
0.04\end{array}$ & $"$ & 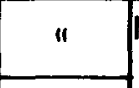 & \multirow{2}{*}{$\mid \begin{array}{c}\text { Inclusions } \\
\mathrm{Eu}_{3} \mathrm{O}_{4} \\
\mathrm{Gd}_{2} \mathrm{O}_{3}\end{array}$} & & & & & & \\
\hline 19 & {$\left[\begin{array}{cc}E U & 0.98 \\
\text { Gd } & 0.04\end{array}\right]$} & " & " & & & & & & & \\
\hline
\end{tabular}

Table I : Characteristic data of the different samples. Final composition of samples $A$ to 10 are estimated by comparison with reference 6 . Gd concentrations of samples 11 to 16 are parts by weight. $E_{A}$ is the activation energy of resistivity $\rho$.

Therefore, we agree with the results of Von Molnar (10) showing that the resistivity depends essentially on the concentration of dopants but is relatively insensi-
$\mathrm{Eu}_{1+\mathrm{x}^{0}} \mathrm{n}^{\circ} \mathrm{IV}-\mathrm{I}$ reported by $/ 6 /$ in figure 7 The carrier concentration $\mathrm{n}$ was deduced from Hall effect measurements when available, i.e. when the resistivity $\rho$ did 
not exceed $10^{5} \Omega \mathrm{cm}$. As an example, we report in figure 6 the temperature dependence of the mobility $\mu$ for the sample $n^{\circ} 8$, deduced from resistivity and Hall effect measurements.

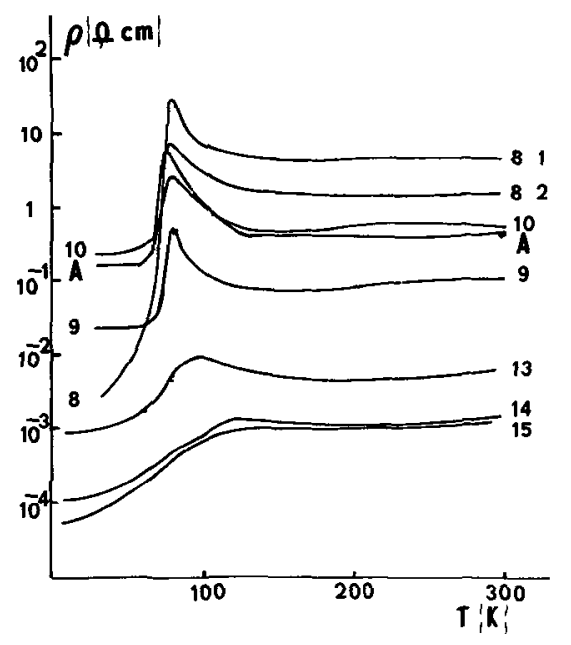

Fig 5. Resistivity versus temperature on "metallic" Euo samples.

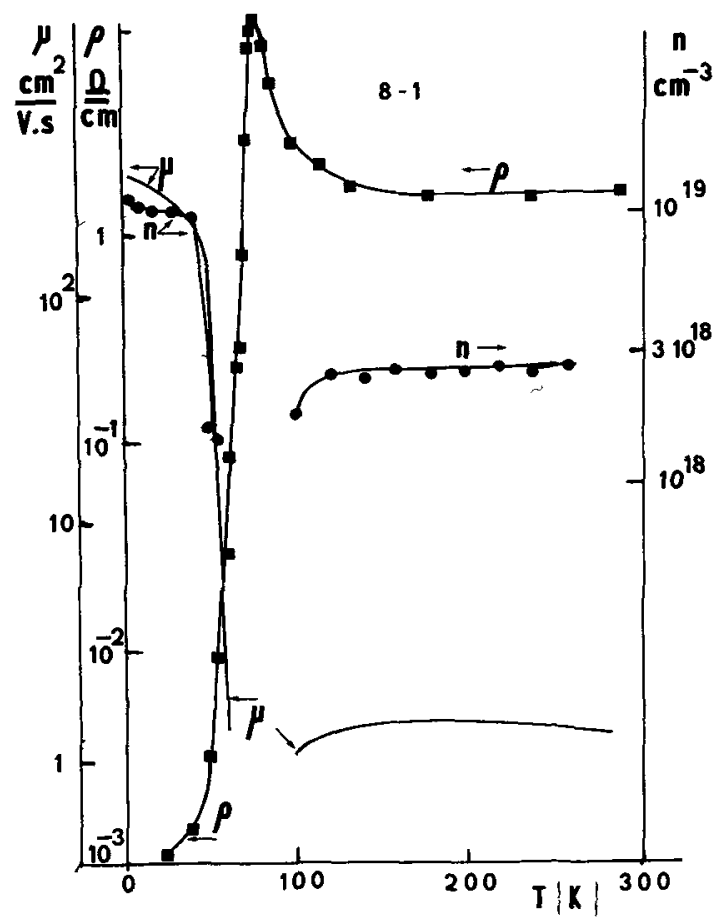

Fig 6. Resistivity carrier concentration and mobility versus temperature on Euo $n^{\circ} 8$.

For more insulating samples the mobility has been estimated from measurements of the photoconductivity $s$ as a function of temperature
(Fig. 7). In effect, it is commonly assumed $/ 11,12,13 /$ that the stationary photoconductivity signals is proportional to $\mu \tau$. The relaxation time $\tau$ of photoexcited carriers is roughly constant in the range $4.2-150 \mathrm{~K}$ $113 /$. It follows that in the critical range $40-80 \mathrm{~K}, \mathrm{~s}$ is proportional to $\mu$. Figure 7 illustrates the similarity between $\mathbf{s}$ and $\mu$ vs. temperature. An important feature is the minimun of mobility near $T_{C}$ which may be imputed to a scattering by spin fluctuations /14/. The ratio between mobilities at high and low temperatures ranging from $10^{-3}$ to $10^{-1}$ is too small to account for the variations of resistivity, so that the MIT is mainly due to a variation of the carrier concentration.

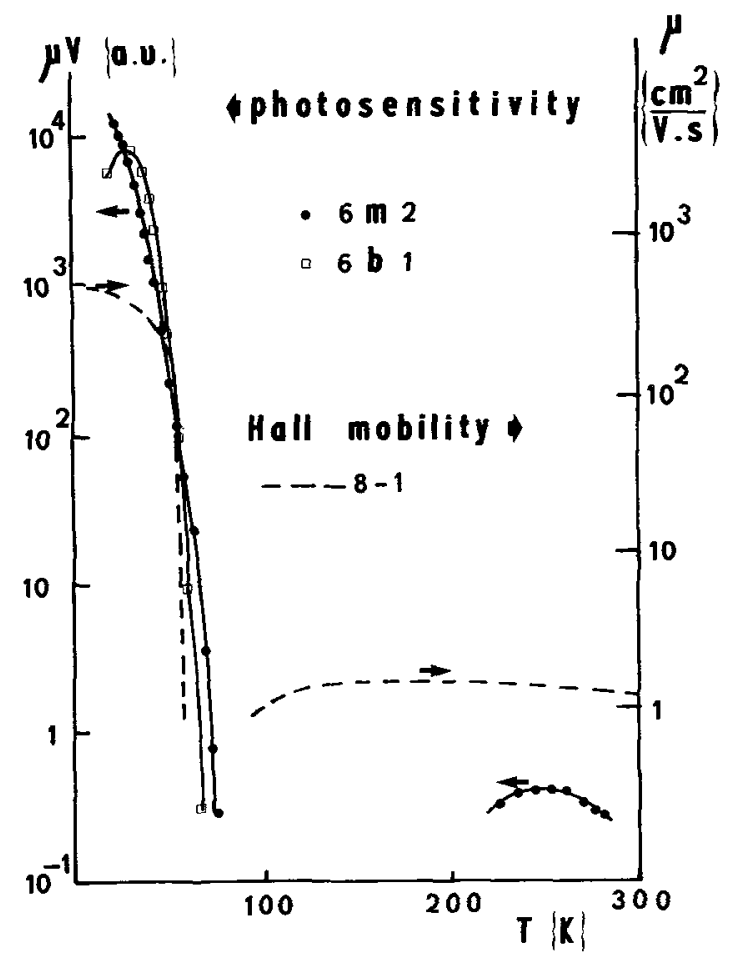

Fig 7.Photosensitivity versus temperature ; comparizon between signals of photsentivity and mobility versus temperature near $T_{C} \cdot(m$ : for middle of $\mathrm{cru}-$ cible and $b$ : for bottom)

4 - Optical properties.- Torrance et al.15/ first observed two absorption peaks at room temperature, located at $1.85 \mu \mathrm{m}$ and $2.20 \mu \mathrm{m}$, in Eu rich samples. They imputed these transitions to a spin flip of the outer electron of the oxygen vacancy. These peaks were also observed even in the metallic configuration by Helten et al./16/ who challenged this 
interpretation since this electron is no longer bound.

To argue this debate, we have performed reflectivity measurements as a function of temperature on the sample $N^{\circ} 5$. Two dips in the reflectivity spectra at $1.85 \mu \mathrm{m}$ and $2.2 \mu \mathrm{m}$ are observed at all temperatures between 4.2 and $300 \mathrm{~K}$ (Fig. 8). At $4.2 \mathrm{~K}$ two other dips are observed at $1.74 \mu \mathrm{m}$ and $2 \mu \mathrm{m}$. The location of the 4 dips is not sensitive to the magnetic field up to $30 \mathrm{kG}$. These results are in good agreement with those obtained on absorption spectia in ref $116 /$.

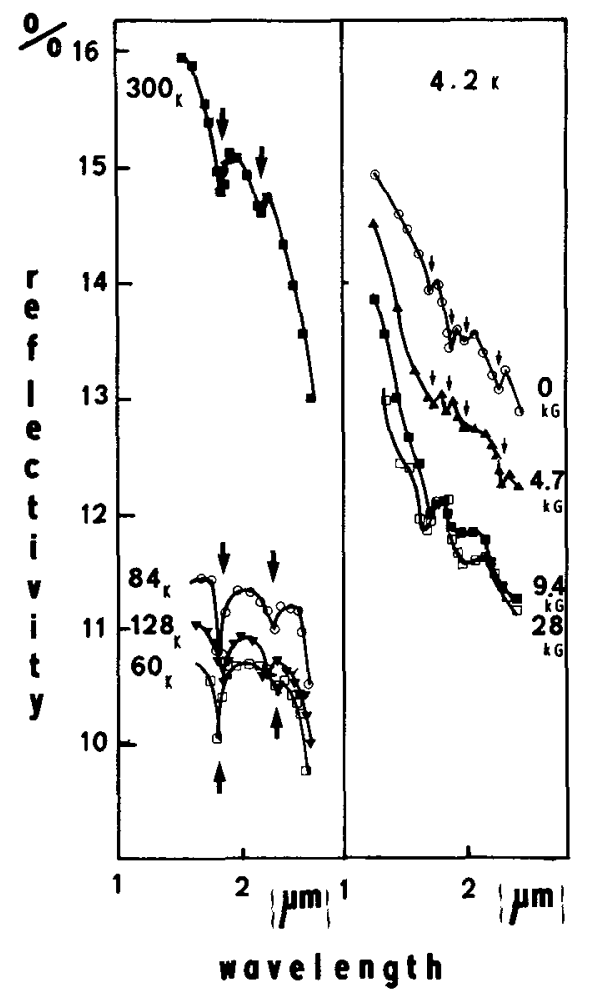

Fig. 8 Reflectivity versus wavelength at different temperatures and at different magnetic fields at 4. $2 \mathrm{~K}$.

5. ivagnetic measurements.- To investigate the correlation between magnetic and transport properties, we have measured the magnetization of various samples with a vibrating sample magnetometer.

For samples $n^{\circ} 5$ to 12 the Brillouin law is satisfied with a Curie temperature $\mathrm{T}_{\mathrm{C}} \not \equiv 70 \mathrm{~K}$. A tail in the magnetization curve of sample $\mathrm{n}^{\circ} 13$ in the vicinity of $70 \mathrm{~K}$ can be assigned to the existence of a small Gd gradientinthe sample, due to the fact that in this sample the carrier concentration is near the critical concentration for indirect exchange (see in the discussion). The curie temperature sharply increases to \# $140 \mathrm{~K}$ in EuO $\mathrm{n}^{\circ} 14$ with a slightly increased electron concentration, and reaches \# $140 \mathrm{~K}$ in Euo $\mathrm{n}^{\circ} 15$. 6. Discussion.- The short range superexchange interactions are responsible for the ferromagnetic ordering at $\mathrm{T}_{\mathrm{C}} \# 70 \mathrm{~K}$ in insulating Euo.

The introduction of free carriers adds an indirect exchange interaction coupling the spins of the electron and Eu atoms according to the law :

$$
-J_{\text {df }} \vec{s}\left(R_{n}\right) \cdot \vec{s}\left(r-R_{n}\right)
$$

where $J_{d f}$ is the atomic exchange constant, $\vec{S}\left(R_{n}\right)$ the spin of the Eu atom on site $R_{n}$ and $\vec{s}$ the spin of the electron. To the second order, in the molecular field approximation, this Hamiltonian leads to the following expression characteristic of the RKKY interaction:

$$
\begin{aligned}
& H_{\text {ex }}=\vec{i}_{, j} J_{\text {eff }}\left(R_{i j}\right) \quad \vec{s}(R i) \cdot \vec{S}(R j) \\
& J_{\text {eff }}\left(R_{i j}\right)=-\left(\frac{J_{d f}}{2 N}\right)^{2} \frac{\sum_{\vec{k}} \frac{n_{k} \vec{q}}{E(\vec{k})-E(\vec{k}+\vec{q})}}{x \exp \left[i \vec{q} \cdot\left(\vec{R}_{i}-\vec{R}_{j}\right)\right]}
\end{aligned}
$$

$N$ is the number of $E u$ atoms, $E(K)$ is the dispersion law of the conduction band and the $\mathrm{n}_{\mathrm{k}}$ are occupation numbers. Further calculations, however, depart from the usual models since they must take into account specific properties of the material arising from the fact that the electron concentration is much smaller than in metals. In particular, the spin splitting of the conduction band, $J_{d f} S$, is larger than the Fermi energy at low enough temperatures, so that the Fermi level crosses the bottom of the spin down conduction subband at a defined temperature below $\mathrm{T}_{\mathrm{C}}$. This implies a change of the carrier statistics, and then, of the indirect exchange interaction $J\left(R_{i j}\right)$ as given by eq. 2. This effect is responsible for the departure of the magnetization curves from the usual Brillouin law evidenced on thin films /17/ and in ref/18/ The increase of $T_{C}$ as a function of $n$ up 
to $143 \mathrm{~K}$ for $\mathrm{n} \neq \neq 5 \times 10^{20} \mathrm{~cm}^{-3}$ is in good agreement with the results of the calculations from eq. $2 / 18 /$ For low concentrations $\left(\mathrm{n}<10^{20} \mathrm{~cm}^{-3}\right)$ the indirect exchange interaction favours the localization of the free carriers around charge centers to build Bound Magnetic Polarons BMP beyond $\neq 50 \mathrm{~K}$, owing to the dependence of $J\left(R_{i j}\right)$ on temperature and on the Eu spin polarization $\sigma$. At high temperature, the ionization energy of the BMP is then essentially magnetic in nature, and is then roughly equal to $\mathrm{J}_{\mathrm{df}} \mathrm{S} / 2 \neq 0.35 \mathrm{eV} / 18 /$.

Another typical property of such materials is the shift of the absorption edge with temperature. This effect was first observed by Busch and al. /19/ and experimentally studied by Freiser and al. $/ 20 /$ for undoped samples. This effect can be imputed to a shift of the bottom of the conduction band due to the exchange interaction /21,22/ For such undoped samples, at $T=0$, the photon energy at the absorption edge is given by : $x u_{v}=E_{g}-\frac{1}{2} J_{d f} S$

Such is not the case for Gd doped Euo, as it has been noticed by schoenes and wachter /23/, who concluded that the increase of $\hbar \omega_{0}$ with the Gd concentration. $x$ at $T=0$ was an evidence for a lowering of magnetic interactions. We do not agree, however, with this interpretation, and impute these phenomena to a Burstein effect $/ 24 /$. More exactly, the photon energy at the absorption edge at $T=0$ in these samples is

$$
\hbar \omega=\hbar \omega_{0}+E_{F}-\Delta E
$$

$E_{F}$ is the Fermi energy, and accounds for the filling up of the conduction band, when a high concentration of $\mathrm{Gd}^{3+}$ ions are introduced in the Euo matrix. This doping is also responsible for a deformation energy $\Delta \mathrm{E}$ which, in first approximation, is given by :

$$
\Delta E=\frac{1}{2} B J^{2}+\Sigma \cap J
$$

$B$ is the bulk modulus, $\Sigma$ the deformation potential, $n$ the concentration of $\mathrm{Gd}^{3+}$ ions and $J$ the elastic deformation which we have assumed to be uniform for simplicity. Minimizing $\Delta \mathrm{E}$ with respect to $J$, we have: $\hbar\left(\omega-\omega_{0}\right)=E_{F}-\frac{\Sigma^{2} n}{B}$
Due to the lack of any experimental data relative to the effect of the introduction of $\mathrm{Gd}$ on $\mathrm{B}$ and $\Sigma$, we have taken for these parameters their value measured in undoped Euo $/ 25 /, i, e, B=1.1 \times 10^{12}$ ergs, $\Sigma=4.8$ eV. This approximation, however, is not expected to be drastic for the present purpose, since $\Delta \mathrm{E}$ is found to be a corrective term in eq. 4 where $\Delta \mathrm{E} \ll \mathrm{E}_{F}$. When the empirical dispersion law of the electrons in Euo given in ref. $/ 26 /$ is chosen to calculate $E_{F}$, we obtain for the blue-shift of the absorption edge with Gd doping at $\mathrm{T}=0: \hbar\left(\omega-\omega_{0}\right)=102 \mathrm{meV}$ for $\mathrm{n}=6 \times 10^{20} \mathrm{~cm}^{-3}$, and $45 \mathrm{meV}$ for $\mathrm{n}=1.6 \times 10^{20} \mathrm{~cm}^{-3}$. This is in fairly good agreement (within $5 \mathrm{meV}$ ) with respect to experimental values of ref. /23/ at $\mathrm{T}=0$. We did not attempt to interpret the temperature dependence of the absorption edge, because the strong distorsion of the absorption spectra with temperature makes its choise rather arbitrary. We can conclude that both magnetic properties; (such as the deviations of the magnetization from the Brillouin law), and the optical properties, (such as the location of the absorption edge at low temperatures for heavily doped Eu0), can be quantitatively explained by our model without referring to any disorder effect.

The spin flip energy of the electron in the BMP is twice as large i.e. $0.6 \mathrm{ev}$, which corresponds to the energy location of the two structures in the optical spectra. That is why some authors $/ 15 /$ assigned these peaks to a spin resonance of the outer electron of BMP, which reverses its spin with respect to the aligned Eu spins inside the polaron. Due to the existence of these structures at low temperature, when the electron is delocalised, Helten et al /16/ suggested that they might involve a $\mathrm{F}^{+}$center, and not the outer electron of the oxygen vacancy. Nevertheless, the calculation of the Fermi energy and of $J\left(R_{i j}\right)$ according to eq. 2 shows that in the metallic configuration, all the conduction electrons are polarized in the spin up subband split from the spin down subband by an energy which is also about $J_{d f} \mathrm{~S}$ according to eq. 1. This suggests that the optical transitions may be considered as an 
exchange resonance of the outer electron of the vacancy, with respect to the Eu spins inside the polaron in the insulating configuration, and with respect to the Eu spins of the whole crystal in the ferromagnetic and metallic configurations. This interpretation has the advantage of giving an overall understanding of magnetic and optical properties, and does not refer to the existence of a F${ }^{+}$center which should imply non forbidden optical transitions with stronger intensities.

To study the variation of $\mathrm{n}$ induced by the existence of the donor level, we have calculated the carrier statistics from the equation of neutrality :

$$
\mathrm{n}_{\mathrm{d}}-\mathrm{p}=\mathrm{n}_{\mathrm{A}}^{+}+\mathrm{n}
$$

$\mathrm{n}_{\mathrm{d}}$ is the density of ionized donor states, $p$ is the density of holes in the $4 f$ level, $\mathrm{n}_{\mathrm{A}}^{+}$is the density of ionized acceptor states and $n$ the density of conduction electron. The results of the calculations depend on the concentration of donor atoms and on their ionization energy $\mathrm{E}_{\mathrm{d}}$ which we suppose equal to

$$
E_{d}=E_{k i n}+E_{C o u}+1 / 2 J_{d f} s(1-\sigma)
$$

at all temperatures. The three terms are respectively kinetic, coulomb and exchange energies. The sum of the two first terms is roughly equal to $17 \mathrm{meV}$ for $T<T_{C}$ when the donor concentration $\mathrm{N}_{\mathrm{D}}$ is smaller than the Mott concentration. At $T=0$, we take into account correlations between donor states according to a law :

$$
\mathrm{E}_{\mathrm{d}}=\mathrm{E}_{\mathrm{d}}^{0}\left(1-\alpha \mathrm{N}_{\mathrm{D}}^{1 / 3}\right)
$$

as in the case of non magnetic semiconductors 127 . For $T>T_{C}$, the radius of the bound orbital is determined by exchange interactions which shrink the orbital; $\mathrm{E}_{\mathrm{kin}}+\mathrm{E}_{\mathrm{Cou}}$ becomes negative and $\mathrm{E}_{\mathrm{d}}$ is then smaller than $J_{d f} S / 2: E_{d} \neq 300 \mathrm{meV}$. Like different authors $/ 28 /$, we admit the existence of a compensating acceptor level with a concentration $\mathrm{N}_{\mathrm{A}}=5 \times 10^{17} \mathrm{~cm}^{-3}$ and an ionization energy equal to half of the energy gap. In fact, the energy location of the acceptor level does not change the values of $n$, because it is far below the bottom of the conduction band. The $4 f$ level is considered as a discrete level due to its small width. To calculate the resistivity we have chosen for the mobility a value equal to $100 \mathrm{~cm}^{2} /$ V.s. at $\mathrm{T}<\mathrm{T}_{\mathrm{C}}$ and to $1 \mathrm{~cm}^{2} / \mathrm{V} . \mathrm{s}$. at $T>T_{C}$, which are typical experimental values (figure 6 and ref./29/). A diagram of the different levels used in the model is drawn in figure 9. A good agreement between experimental and calculated resistivity curves is observed in the whole range 4.2 - $300 \mathrm{~K}$ for samples which are not metallic at $\mathrm{T}>\mathrm{T}_{\mathrm{C}}$, results are plotted in figure 10 for a few of our samples and for 2 samples of ref. $/ 6 /$.

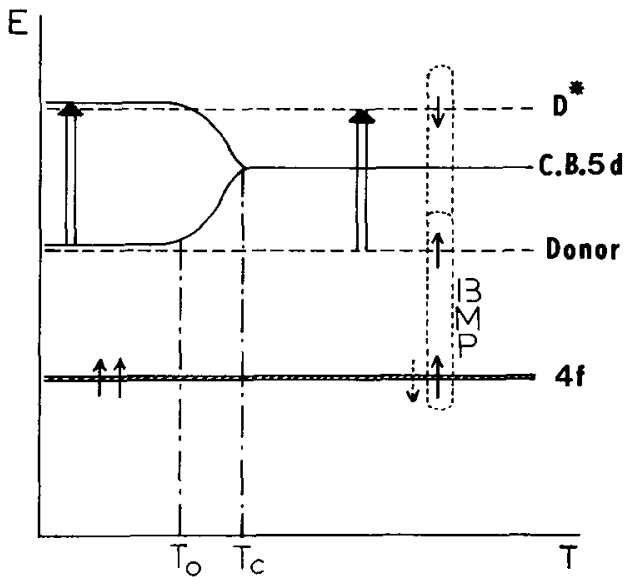

Fig 9. Diagram illustrating the model.

in particular, the activation energy Ea at room temperature $\rho(T){ }_{0} \exp \left(-\frac{E_{a}}{k T}\right)$ continuously varies from $300 \mathrm{meV}$ to, $00 \mathrm{meV}$ when the degree of compensation $\mathrm{N}_{\mathrm{A} / \mathrm{N}_{\mathrm{D}}}$ changes from 0.99 to 1.01 . This effect is due to the contribution of $4 \mathrm{f}$ states in the carrier statistics although the gap $\neq 1.1 \mathrm{eV}$ is large because the density of $4 \mathrm{f}$ states is very large. In this simple model, the behaviour of the resistivity of the sample with a vanishing activation energy in the paramagnetic configuration cannot be understood. Nevertheless, an enlargement of this model /30/ taking into account the mánetic entropy connected with a BMP shows that only few BMP are delocalized at $\mathrm{T}>\mathrm{T}_{\mathrm{C}^{\prime}}$ ' whereas all the electrons are delocalized at $T<T_{C}$ when the concentration $N_{D}$ exceeds the critical concentration of the metal 
insulator transition. This result is in good agreement with the fact that the electron concentration measured at $T<T_{C}$ is lower than when measured at $\mathrm{T}>\mathrm{T}_{\mathrm{C}}$ on such samples $/ 29 /$. This also explains the existence of structures in optical spectra at 1.85 and $2.20 \mathrm{~m}$ on an Eu rich EuO sample with a vanishing activation energy at room temperature in ref $/ 16 /$.

Finally, we can also understand the existence of four structures of low temperature $131 /$. Due to the fact that the $5 \mathrm{~d}$ bands build six $t_{2 g}$ subbands and with the results of Schoenes and Nolting /32/ (in Eus) showing a crossing of spectral weights at $T<30 \mathrm{~K}$, we can expect that extra optical transitions between spin up and spin down subbands appear. The disappearance of the extra structure at $5750 \mathrm{~cm}^{-1}$ near $35 \mathrm{~K}$ observed by Helten and al. is an argument for this model.

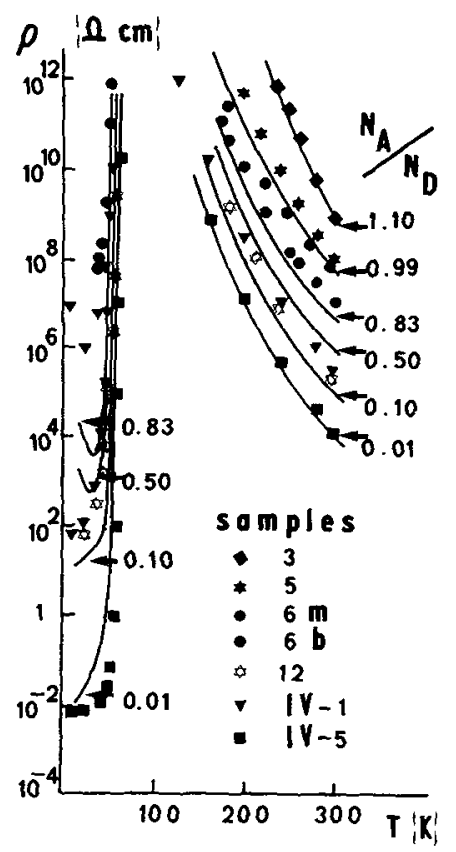

Fig. 10 Experimental and calculated resistivities versus temperature. Samples IV -1 and IV -5 are from Ref. 6.

\section{References}

/1/ Oliver,. M.R., Dimmock, J.O., Reed,T.B., IBM J. Res. Dev, 14 (1970) 276.

Oliver, M.R., Thesis, M.I.T. (1970)Unpublished.

Oliver, M.R., Dimmock, J.O., MC. Whorter A.I., Reed, T.B., Phys. Rev. B5, (1972) 1087.

12/ Torrance, J.B., Shafer, M.W., Mc.Guire, T.R., Phys. Rev. Lett. 29, (1972) II68 Leroux Hugon, P., Phys. Rev. Lett 29 (1972) 939 .

/3/ Guergi, C.F., Shafer, M.W., J. App1.Phys. 37 (1966) 1406.

/4/ Llinares, C., Desfours, J.P., Nadai,J.P., Godart, C., Percheron, A., Achard, J.C., Phys. Status Solidi 25a (1974) 185.

15/ Fischer, K.J., Helten, M., Saftic, B., $1^{\text {st European Conf. on Crystal Growth }}$ ECCG 1 in Zurich - sept. 1976.

16/ Shafer, M.W., Torrance, J.B., Penney, T., J. Phys. Chem. Solids 33 (1972) 2251 .

17/ Fatseas, G., Thesis Paris_ VI, mars 1973

18/ Huber, E.J., Holley, C.E., J. Chem. Thermodyn 1 (1969) 301.

19/ Samokhvalov, A.A., Gizhevskii, B.A. Simonova, M.I., Solin, N.I., Sov. Phys. Solid state 14 (1972) 230 .

/10/Von Molnar, S., IBM J. Rev. Dev. 14 (1970) 269.

/11/ Llinares, C., Thesis U.S.T.L. Montpellier (1973)- Unpublished

/12/ Bachmann, R., Wachter, P., Solid State Commun 6 (1968) 711 .

113/ Ilinares, C., Gouskov, L., Duchemin, C., Bordure, G., J. Phys. Chem. Solids 36 (1975) 567.

14/ Fisher, M., Langer, J.S., Phys. Rev. Lett. 20 (I968) 665.

15/ Torrance, J.B., Shafer; M.W., MC. Guire, T.R., Abstract in Bull. Amer. Phys. Soc. 17 (i 972 ) 315 .

/16/ Helten, M., Grunberg, P., Zinn, W., Physica $89 \mathrm{~B}$ (1977) 63 .

117/ Massenet, O., Capiomont, Y., Nguyen Van Dang,J., J. Appl. Phys. 46, (1974) 3593 .

118/ Mauger, A., Godart, C., Escorne,M., Achard, J.C., Desfours, J.P., J. Phys. 39 (1978) 1125 ; Journal de Physique, this tome.

119/ Busch, G. , Junod, P., Wachter, P., Phys. Lett. 12, (1964) il.

/20/ Freiser, M.J., Holtzberg,F., Methfessel, S., Pettit, G.O. Shafer, M.W., Suits, J.C., Helv. Phys. Acta 41 (1968) 832

/21/ Rys, F., Helmann, J.S., Baltensperger, W., Phys. Kondens. Mater 6 (1967) 105 Baltensperger, W., J. Appl. Phys. 41 (1970) 1052 . 
122/ Haas, C., IEEE Trans. Magn. 5 (1969) 487 Phys. Rev. 168 (1968) 531.

/23/ Schoenes, J., Wachter, P., Phys. Rev. B9 (1974) 3097 .

/24/ Burstein, E., Phys. Rev. 93 (1954) 632

/25/ Jayaraman, A., Sink, A.K., Chatterjee, A., Usha Devi, S., Phys. Rev. B9 (1974) 2513.

/26/ Mauger, A., Phys. Status. Solidi 84 b, (1977) 761 .

/27/ Woodbury, Aven, Phys. Rev. B9 (1974) 5195.

/28/ Penney, T., Shafer, M.W., Torrance, J.B., phys. Rev. B5 (1972) 3669. and ref / $/ 0 /$

/29/ Shapira, Y., Foner, S., Reed, T.B., Phys. Rev. B8 (1973) 2299.

130/ Mauger, A., Godart, C., To be published.

/31/ Godart, C. Mauger, A., Escorne, M., Achard, J.C., XIV th Proceedings of the Rare Earth Research Conference, North Dakota, U.S.A., June 1979

/32/ Schoenes, J., Nolting, W., J. Appl. Phys. 49 (1978) 1466. 